\title{
When Coverage Expands: Children's Health Insurance Program as a Natural Experiment in Use of Health Care Services
}

Adrianne Haggins, MD, MS, Stephen Patrick, MD, MPH, MS, Sonya Demonner, MPH, and Matthew M. Davis, MD, MAPP

\begin{abstract}
Background: Expanding insurance coverage is designed to improve access to primary care and reduce use of emergency department (ED) services. Whether expanding coverage achieves this is of paramount importance as the United States prepares for the Affordable Care Act.

Objectives: Emergency and outpatient department use was examined after the State Children's Health Insurance Program (CHIP) coverage expansion, focusing on adolescents (a major target group for CHIP) versus young adults (not targeted). The hypothesis was that coverage would increase use of outpatient services, and ED use would decrease.

Methods: Using the National Ambulatory Medical Care Survey (NAMCS) and the National Hospital Ambulatory Medical Care Survey (NHAMCS), the years 1992-1996 were analyzed as baseline and then compared to use patterns in 1999-2009, after the CHIP launch. Primary outcomes were populationadjusted annual visits to ED versus nonemergency outpatient settings. Interrupted time series were performed on use rates to ED and outpatient departments between adolescents (11 to 18 years old) and young adults (19 to 29 years old) in the pre-CHIP and CHIP periods. Outpatient-to-ED ratios were calculated and compared across time periods. A stratified analysis by payer and sex was also performed.

Results: The mean number of outpatient adolescent visits increased by 299 visits per 1,000 persons (95\% confidence interval $[\mathrm{CI}]=140$ to 457 ), while there was no statistically significant increase in young adult outpatient visits across time periods. There was no statistically significant change in the mean number of adolescent ED visits across time periods, while young adult ED use increased by 48 visits per 1,000 persons $(95 \% \mathrm{CI}=24$ to 73$)$. The adolescent outpatient-to-ED ratio increased by $1.0(95 \% \mathrm{CI}=0.49$ to 1.6), while the young adults ratio decreased by 0.53 across time periods ( $95 \% \mathrm{CI}=-0.90$ to -0.16 ).

Conclusions: Since CHIP, adolescent non-ED outpatient visits have increased, while ED visits have remained unchanged. In comparison to young adults, expanding insurance coverage to adolescents improved use of health care services and suggests a shift to non-ED settings. Expanding insurance through the Affordable Care Act of 2010 will likely increase use of outpatient services, but may not decrease ED volumes.
\end{abstract}

ACADEMIC EMERGENCY MEDICINE 2013; 20:1026-1032 @ 2013 by the Society for Academic Emergency Medicine

$\mathrm{P}$

roviding health insurance coverage to previously uninsured populations is designed to facilitate the use of health care services by minimizing finan- cial barriers to accessing care, especially within primary care settings. In addition, the Department of Health and Human Services envisions that enhancing delivery of

From the Department of Emergency Medicine (AH), the Robert Wood Johnson Foundation Clinical Scholars Program (AH, SP, SD, MMD), the Department of Pediatrics and Communicable Diseases (SP, MMD), the Division of Neonatal-Perinatal Medicine (SP), the Veterans Affairs Center for Clinical Management Research (SD), and the Department of Internal Medicine and Gerald R. Ford School of Public Policy (MMD), University of Michigan, Ann Arbor, MI.

Received February 15, 2013; revision received April 16, 2013; accepted April 22, 2013.

Presented at The Robert Wood Johnson Foundation Clinical Scholars National Meeting, November 2011; the Society for Academic Emergency Medicine Annual Meeting, May 2012; and the Academy Health Annual Academic Research Meeting, June 2012.

Funded through the Robert Wood Johnson Foundation Clinical Scholars Program. Dr. Patrick has been a consultant with Vermont Oxford Network. The other authors have no disclosures or conflicts of interest to report.

Supervising Editor: Lawrence M. Lewis, MD.

Address for correspondence and reprints: Adrianne Haggins, MD, MS; e-mail: ahaggins@med.umich.edu. 
high-quality care in primary care settings will reduce reliance on emergency departments (EDs). ${ }^{1}$ Determining whether expanding coverage achieves this goal of shifting patients to nonemergency outpatient settings is of paramount importance as the United States prepares to implement the Affordable Care Act, a landmark initiative to address the uninsured rate in the United States.

In 1997, the State Children's Health Insurance Program (SCHIP; when it was reauthorized in 2009, SCHIP was reidentified as CHIP, but we use the latter acronym throughout the article to refer to the original program as well) was enacted as a national initiative to increase insurance among children by providing coverage to children not historically targeted by Medicaid. As part of the program, income-eligibility thresholds were increased for children in all age groups, with the most notable increases seen in adolescents. ${ }^{2}$ Through streamlined enrollment and outreach efforts, the provision of coverage through CHIP along with Medicaid resulted in a decrease in uninsured rates among near-poor children. ${ }^{36}$ Since the implementation of CHIP, several state-level analyses have found that newly enrolled children have improved access to a usual source of care and specialty care, as well as preventive care visits, and have also found higher parental satisfaction with the quality of health care services. ${ }^{2,7-12}$ However, previous state-level analyses of CHIP and its effect on ED use vary broadly, finding no change, ${ }^{10}$ to increased use in children under 5 years old, ${ }^{8}$ to decreased use. ${ }^{7-9}$ Analyses using nationally representative household surveys found that CHIP increased physician outpatient visits and well-child encounters from 1997 to 2003; however, concurrent effects on ED visits were not examined. ${ }^{2,11}$

Emergency department use is an area of major policy concern, given the high costs of ED care overall ${ }^{13}$ and the potential for newly acquired coverage to lead to increasing numbers of ED visits at the population level. ${ }^{14}$ Therefore, we empirically assessed CHIP, the last national program that broadly expanded insurance coverage, and its effect on ED and non-ED use, as a natural experiment. Although CHIP was more narrowly targeted in its coverage efforts than the Affordable Care Act, it was similarly directed to provide coverage to populations predominantly unserved by the private and public coverage options available at the time of its enactment.

\section{METHODS}

\section{Study Design}

This was a retrospective cohort analysis of ambulatory visits, including ED and non-ED outpatient settings, using data from the National Ambulatory Medical Care Survey (NAMCS) and the National Hospital Ambulatory Medical Care Survey (NHAMCS). The National Center for Health Statistics (NCHS) compiles both surveys to provide comprehensive and nationally representative data sources regarding ambulatory care use. They are annual cross-sectional surveys using nationally representative probability samples of physician visits to nonfederal clinics and short-stay hospitals. ${ }^{15}$

\section{ED and Non-ED Outpatient Visits}

The NAMCS provides a sample of office-based visits to private physicians and community health centers, while the NHAMCS includes visits to hospital-based outpatient departments and EDs. According to the NCHS, visits prioritized for data collection are those where direct patient care is delivered. ED visits and outpatient visits are available for survey years 1992 through 2009permitting assessment of years of use patterns prior to and after CHIP legislation. Therefore, years 1992 to 1996 were used to establish a baseline utilization trend prior to the CHIP legislation, which was then compared with visit patterns in 1999 through 2009. To allow time for implementation, visits from years 1997 and 1998 were excluded from analysis.

Data from NAMCS and NHAMCS can be used for calculation of national estimates, ${ }^{16,17}$ based on weights from the NCHS that take into account nonresponse, the probability of being sampled, and a ratio adjustment for physicians within the specialty groups. For visits to ED and hospital-based outpatient departments (i.e., primary care or subspecialty care settings within hospitals) in the NHAMCS survey, similar weights are available that additionally account for the number of hospitals within the region and annual volume of hospital visits. According to our institutional review board, our study did not require approval, as the data used are publicly available and de-identified to prevent linking of information directly to individual patients.

\section{Measures}

The primary study outcomes were population-adjusted annual visit rates to EDs versus nonemergency outpatient settings, generated from NAMCS and NHAMCS visit frequencies divided by annual national population estimates by age group from the U.S. Census Bureau Current Population Survey. Outpatient visits were defined as a pooled sample (NAMCS + NHAMCS) of visits to private physician offices, community health centers, and hospital-based outpatient departments.

Our population of primary interest was adolescents, defined here as 11 to 18 years old, based on the Guidelines for Adolescent Preventive Services (GAPS), ${ }^{18}$ and accounting for age-eligibility criteria for CHIP coverage. ${ }^{19}$ Previous studies highlighted high rates of uninsured adolescents ${ }^{20}$ prior to the CHIP legislation, particularly among the poor $(<100 \%$ of the federal poverty level) and near-poor (100\% to $199 \%$ of the federal poverty level). ${ }^{21}$ Several other investigators highlighted trends of underuse of primary care services for this age group, $^{22,23}$ and therefore our analysis was focused primarily on the effect of CHIP on adolescents' trends in use of health care services.

For purposes of comparison, trends of adolescent ambulatory care use were compared with those of young adults 19 to 29 years old. We considered young adults an ideal comparison group to assess for secular trends, as this age group is similar to adolescents in terms of general health and insurance coverage in the pre-CHIP period, yet was not a primary target for coverage under CHIP. ${ }^{24}$ The authors note here that a small group of states used federal funds allotted under CHIP to cover childless adults, but the small size of these initiatives related to CHIP overall is not expected to affect the analysis and would, after all, bias toward finding no difference between adolescent and young adult health care use patterns. 


\section{Data Analysis}

Our analysis includes descriptive statistics of weighted visits reflecting national estimates by care setting, as well as a summary of demographics across time periods. To assess the effect of CHIP policy on trends of health care use, we performed segmented time-series analyses ${ }^{25}$ on use rates of adolescents and young adults to ED and outpatient settings in the pre-CHIP (1992 to 1996) and CHIP implementation (1999 to 2009) periods. For the 1992 data set, a weighted estimate variable does not exist for the NAMCS data set, and therefore this year was excluded from our analyses of the total national outpatient visit estimates and time-series analyses (but included for ED analyses, available from NHAMCS data).

In addition, we sought to analyze how outpatient use compares with ED use on a population level. We calculated a ratio of outpatient-to-ED visits to assess the relationship of change in annual visits between the two ambulatory settings, as an informative composite measure of ED and outpatient visits over the pre-CHIP and CHIP implementation time periods.

We also calculated the difference between the adolescent and young adult annual visits within the ED and non-ED outpatient settings for the pre-CHIP and CHIP implementation periods. This difference-in-difference analysis allowed us to control for secular trends in the use of medical services, comparing adolescents expected to benefit as a group from an expansion of coverage versus young adults not targeted by CHIP. Finally, we performed a stratified analysis of trends in ED and outpatient use by payer and sex.
Linear regression was used to assess the statistical significance in the change from the pre-CHIP and CHIP implementation time periods for all primary outcomes: mean number of annual visits, mean ratio of outpatientto-ED visits, and difference-in-difference rates. All analyses were performed using Stata 12.0 (StataCorp, College Station, TX), incorporating the complex multistage sampling design and survey weighting estimates of the NAMCS and NHAMCS survey data.

\section{RESULTS}

Patterns of Visits in Pre-CHIP Versus CHIP Periods

Adolescents made an estimated 321 ED visits per 1000 annually during the pre-CHIP era and 316 per 1,000 after implementation. Annual outpatient visits changed from 1,740 to 2,038 per 1,000 adolescents across time periods. The proportion of uninsured adolescent visits decreased from $15 \%$ to $6 \%$. Adolescent visits with Medicaid/CHIP coverage increased from $18 \%$ to $24 \%$ (Table 1).

In contrast, young adults made approximately 429 ED visits per 1,000 annually pre-CHIP versus 478 per 1,000 during CHIP implementation. For outpatient visits, there were an estimated 2,099 visits per 1,000 young adults pre-CHIP versus 2,070 per 1,000 since CHIP. Across time periods, the proportion of young adult visits where the patient was uninsured changed from 17 to 14, and visits with Medicaid/CHIP coverage changed from 18 to 19.

Among adolescents, the mean number of populationadjusted outpatient visits increased by 299 visits per 1,000 adolescents $(95 \%$ confidence interval $[\mathrm{CI}]=140$ to

Table 1

Characteristics of Adolescent and Adult Emergency and Nonemergency Outpatient Visits

\begin{tabular}{|c|c|c|c|c|}
\hline \multirow[b]{2}{*}{ Visit Characteristics } & \multicolumn{2}{|c|}{ Pre-CHIP, 1992-1996 } & \multicolumn{2}{|c|}{ Post-implementation, 1999-2009 } \\
\hline & $11-18$ yr & $19-29 \mathrm{yr}$ & $11-18$ yr & $19-29 \mathrm{yr}$ \\
\hline \multicolumn{5}{|c|}{ Weighted visits per 1,000 persons in the population } \\
\hline Annual mean ED visits (SD) & $320.5(15.4)$ & $429.4(17.6)$ & $315.6(20.2)$ & $477.5(22.4)$ \\
\hline $\begin{array}{l}\text { Annual mean non-ED } \\
\text { outpatient }{ }^{* \dagger} \text { visits (SD) }\end{array}$ & $1,739.5(15.0)$ & $2,099.2(123.2)$ & $2,038.2(143.4)$ & $2,070.3(58.7)$ \\
\hline Age $(y r)$, mean (SD) & $15(2.3)$ & $24(3.1)$ & $15(2.3)$ & $24(3.2)$ \\
\hline \multicolumn{5}{|l|}{$\operatorname{Sex}(\%)$} \\
\hline Male & 47 & 31 & 48 & 30 \\
\hline Female & 53 & 69 & 52 & 70 \\
\hline \multicolumn{5}{|l|}{ Race/ethnicity (\%) } \\
\hline White non-Hispanic & 73 & 71 & 63 & 59 \\
\hline Black non-Hispanic & 12 & 14 & 19 & 20 \\
\hline Other non-Hispanic & 3 & 4 & 6 & 6 \\
\hline Hispanic & 11 & 12 & 12 & 15 \\
\hline \multicolumn{5}{|l|}{ Insurance (\%) } \\
\hline Private & 63 & 58 & 66 & 62 \\
\hline CHIP/Medicaid & 18 & 18 & 24 & 19 \\
\hline Medicare & 1 & 1 & 1 & 2 \\
\hline Uninsured & 15 & 17 & 6 & 14 \\
\hline Other & 3 & 5 & 3 & 4 \\
\hline \multicolumn{5}{|c|}{$\begin{array}{l}\text { Total visits are weighted and adjusted for population using the U.S. Census Bureau annual estimates of resident population, } \\
\text { then rounded to nearest tenth; demographics for sex and payer have been rounded to nearest whole number. } \\
\text { CHIP=Children's Health Insurance Program. } \\
\text { *Outpatient visits may be underestimated due to absence of the weighting variable in the NAMCS data set for } 1992 \text {. Therefore, } \\
\text { since outpatient population estimates for visits in } 1992 \text { are unavailable, } 1992 \text { data were excluded from outpatient analyses and } \\
\text { descriptive statistics. } \\
\text { †Outpatient visits where direct patient care was delivered, excluding EDs. }\end{array}$} \\
\hline
\end{tabular}


457) from the pre-CHIP to CHIP period. In contrast, for young adults, there was no statistically significant increase in outpatient visits over the same time period (Figure 1). Meanwhile, there was no statistically significant change in the mean number of adolescent ED visits after CHIP implementation (Figure 2). In contrast, the mean population-adjusted annual number of ED visits for young adults increased by 48 visits per 1,000 (95\% $\mathrm{CI}=24$ to 73; Figure 2).

We also perform stratified analysis of the trends in ED and outpatient use by payer and sex across time periods (data not shown). For adolescents with Medicaid/CHIP coverage, ED visits did not change significantly, while outpatient visits increased by 480 per 1,000 adolescents (95\% CI $=101$ to 857). Concurrent trends in privately insured adolescent outpatient visits demonstrated an increase by 364 per 1,000 adolescents (95\%

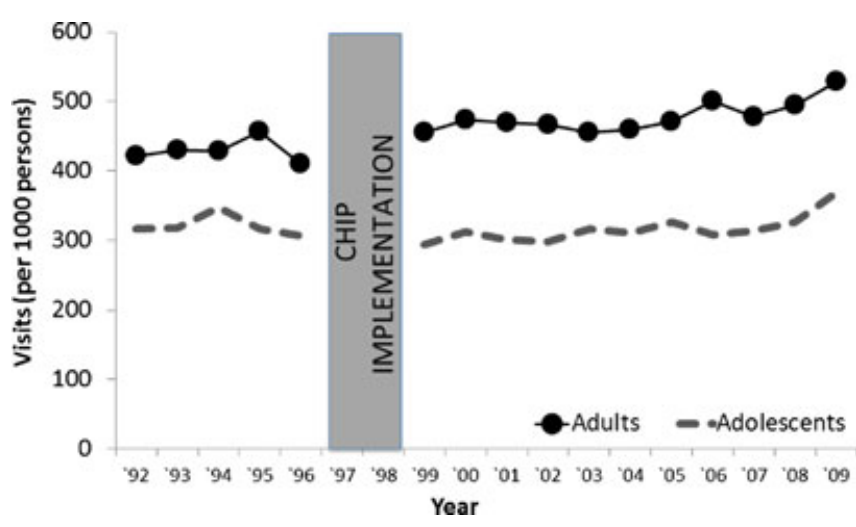

Figure 1. Outpatient use by age group over time. Adult (defined as 19- to 29-year-olds) mean number of outpatient visits decreased by 28 visits per 1,000 persons annually from preCHIP to post-implementation period $(95 \% \mathrm{Cl}=-128$ to 70$)$; $\mathrm{p}$ value not significant. Adolescent mean number of outpatient visits increased by 299 per 1,000 annually $(95 \% \mathrm{Cl}=140$ to 457$)$; significant at $p=0.001$. Note the 1992 NAMCS data set is missing the weighting variable and is therefore excluded from analysis. CHIP = Children's Health Insurance Program; NAM$\mathrm{CS}=$ National Ambulatory Medical Care Survey.

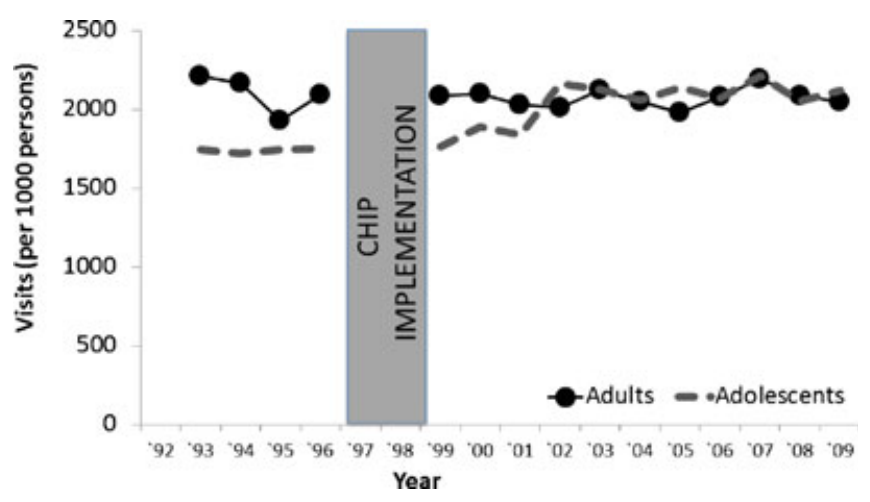

Figure 2. ED use by age group over time. Adolescent mean number of ED visits decreased by five visits per 1,000 annually $(95 \% \mathrm{Cl}=-26$ to 17$)$; $\mathrm{p}$-value not significant. Adult (defined as 19 to 29 year olds) mean number of ED visits increased by 48 per 1,000 annually $(95 \% \mathrm{Cl}=24$ to 73 ) from the pre-CHIP to post implementation period; significant at $\mathrm{p}=0.001$. CHIP $=$ Children's Health Insurance Program.
$\mathrm{CI}=158$ to 569 ), with a decrease in ED visits by 26 per 1,000 adolescents $(95 \% \mathrm{CI}=-39$ to -12$)$. ED visits by uninsured adolescents did not change significantly; however, outpatient visits by uninsured adolescents decreased by 775 per 1,000 after implementation of CHIP (95\% CI $=-1,070$ to -440$)$.

For comparison, health care use for young adults with Medicaid/CHIP coverage did not show a statistically significant change in outpatient visits; however, ED visits increased by 213 visits per 1,000 young adults (95\% CI $=116$ to 310$)$ across time periods. Privately insured young adult outpatient visits increased by 151 visits $(95 \% \mathrm{CI}=28$ to 274$)$, while $\mathrm{ED}$ visits did not change significantly over time. Outpatient visits for uninsured young adults decreased by 424 visits per 1,000 (95\% CI $=-536$ to -311$)$, and ED increased by 132 visits per 1,000 (95\% CI = 83 to 181$)$.

Analyses of trends by sex did not show a statistically significant change in female adolescent ED visits; however, outpatient visits increased by 306 visits per 1,000 (95\% CI $=146$ to 464$)$. Similarly, ED visits by adolescent males did not change significantly, while outpatient visits increased by 304 per 1,000 (95\% CI = 124 to 483). As for young adults during the same time periods, ED visits increased by 100 per 1,000 young adult females $(95 \% \mathrm{CI}=60$ to 140$)$, without a statistically significant change in female outpatient visits. There was no statistically significant change in male ED or outpatient visits over time.

\section{Changing Ratios of Outpatient-to-Emergency Visits with CHIP}

The outpatient-to-ED visit ratio for adolescents increased significantly by $1.04(95 \% \mathrm{CI}=0.49$ to 1.59$)$ from the pre-CHIP period (ratio $=5.3$ ) to CHIP period (ratio $=6.3$; Figure 3 ). In contrast, the outpatient-to-ED ratio for young adults decreased significantly by -0.53 (95\% CI $=-0.90$ to -0.16 ; Figure 3 ).

Stated another way, with CHIP the difference-in-difference for adolescents versus young adults was 328 more outpatient visits annually per 1,000 adolescents (95\% CI $=208.96$ to 446.02$)$ and 53 fewer ED visits annually per 1,000 adolescents $(95 \% \mathrm{CI}=-65.30$, to 40.53; Table 2). These summary comparisons highlight the diverging health care utilization patterns among adolescents versus young adults with the implementation of CHIP.

\section{DISCUSSION}

In this study, we sought to evaluate the effect of CHIP on use of primary, outpatient specialty care, and ED services to illustrate the changing demands on the ambulatory health care system during an era of health care coverage reform. Prior to original CHIP legislation, Newacheck and colleagues ${ }^{26}$ demonstrated the nowfamiliar observation that insured children were more likely to have contact with physicians, a usual source care, access to after-hours care, and less unmet need versus uninsured peers. Similarly, in another analysis using the National Health Interview Survey, Lieu et al. ${ }^{27}$ found that adolescents with public and private insurance had higher numbers of visits for routine care, and a 


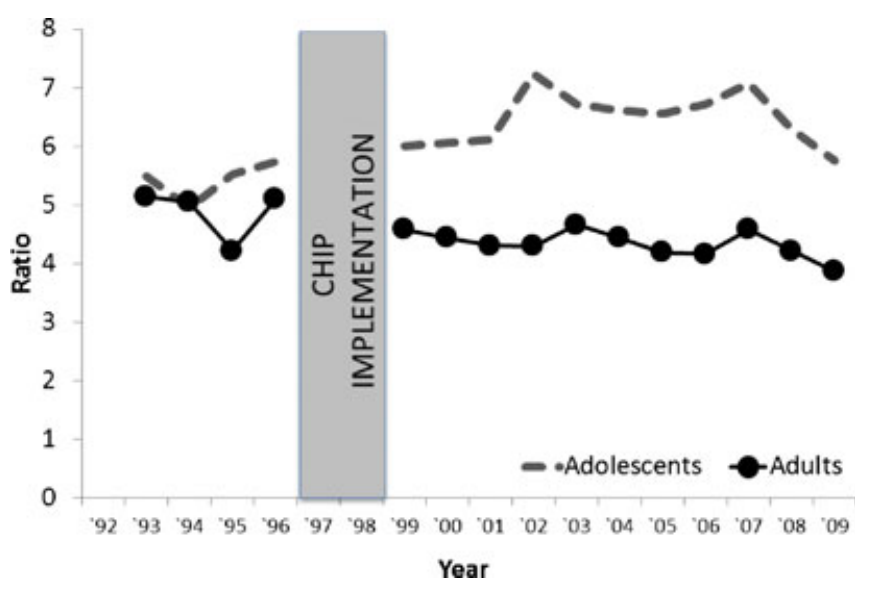

Figure 3. Outpatient-to-ED ratio by age group over time. Adolescent mean outpatient:ED ratio changed by $+1.0(95 \% \mathrm{Cl}=0.5$ to 1.6) annually from pre-CHIP to post-implementation period. Adult (defined as 19- to 29 -year-olds) mean outpatient:ED ratio changed by -0.5 annually $(95 \% \mathrm{Cl}=-0.9$ to -0.2$)$. Both significant at $p<0.05$. Note that the 1992 NAMCS data set is missing the weighting variable and is therefore excluded from analysis. CHIP $=$ Children's Health Insurance Program; NAMCS $=$ National Ambulatory Medical Care Survey.

greater likelihood of having a usual source of care, compared to their uninsured counterparts.

Our study found, with the implementation of CHIP, that adolescent overall visits to non-ED outpatient settings have significantly increased, with the predominant increase seen among adolescents with Medicaid/CHIP coverage, while ED visit rates have remained relatively unchanged. Consistent with our study findings, other investigators have found that doctor visits for nonemergency health care among older children (6 to 17 years of age) have increased since expanding children's health care coverage through CHIP. ${ }^{2}$ Kenney's analysis of CHIP's effects across 10 states also found that enrolled children were more likely to have improved access to private physician offices as their usual source of care. ${ }^{9}$

Our study builds on this prior work by using a different national data source over more years, including the pre-CHIP era, and dual investigation of the outpatient and ED settings. The relatively unchanging volume of ED visits for adolescents after CHIP implementation in our study is consistent with an analysis of the New York
CHIP program, which did not find a difference in use of acute care and emergency services one year after enrollment. ${ }^{10}$ In contrast, a separate 1 -year assessment of newly enrolled children in a North Carolina CHIP program found an $11 \%$ increase in parents reporting use of private physicians for acute care and a decrease in ED visits for older children ages 6 to 18 years whose only access to the health system or acute care services was the ED. ${ }^{8}$ One of the salient aspects of our analysis is that it is essential to consider that the effect of health care reform on altering patterns of use requires time to materialize, and that 1 year is not sufficient to capture these downstream effects. Therefore, our study adds to the existing literature by providing insight into the implications of health care reform on ED trends over a more extended time period, aggregated at the national level.

Our results also contribute to the growing, mixed literature regarding ED patterns after health care coverage expansions. An analysis of Massachusetts' 2006 health care reform policy on nonelderly adult ED use at 11 institutions found that the volume of ED visits did not decrease after implementation of near universal health insurance coverage. $^{28}$ In a separate study, Miller $^{29}$ performed a county-level analysis of ED visits to all hospitals in Massachusetts over the years 2002 through 2008 and compared them with visits in Rhode Island, Vermont, Connecticut, and New Jersey. There was no comparative reduction in overall ED visits in Massachusetts when comparing utilization trends across time periods or between states. In the recent Oregon health insurance experiment, there was a $35 \%$ increase in use of outpatient care without a significant difference in ED use among newly enrolled Medicaid patients. ${ }^{30,31}$ Meanwhile, an annual survey of nonelderly Massachusetts adults initiated prior to health reform implementation noted a decrease in reported ED use in $2010 .{ }^{32}$ Our findings highlight a central theme in the literature to date, which is that decreasing ED visit volumes-promoted by some as a benefit of coverage expansions-may not be realized among populations that experience new coverage.

ED volume is an important metric, but is only one of several factors that must be taken into account when assessing the effects of future health reform initiatives. To better understand the effects of health care reform on demand for ED versus outpatient services, it will be

Table 2

Comparing Pre-CHIP to Post-implementation CHIP Era: Incremental Difference-in-difference in Number of Visits Made by Adolescents Versus Adults

\begin{tabular}{|c|c|c|c|c|c|}
\hline Variable & $\begin{array}{l}\text { Implementation } \\
\text { Difference for } \\
11-18 \text { yr old }\end{array}$ & $\begin{array}{l}\text { Implementation } \\
\text { Difference for } \\
19-29 \text { yr Old }\end{array}$ & $\begin{array}{l}\text { Difference-in- } \\
\text { difference } \\
\text { Between Age } \\
\text { Groups }\end{array}$ & $\begin{array}{l}\text { Difference-in- } \\
\text { difference } \\
95 \% \mathrm{Cl}\end{array}$ & $\mathrm{p}$-value \\
\hline $\begin{array}{l}\text { ED visits } \\
\text { Non-ED } \\
\text { outpatient* visits }\end{array}$ & $\begin{array}{r}-4.8 \\
+298.7\end{array}$ & $\begin{array}{l}+48.1 \\
-28.8\end{array}$ & $\begin{array}{r}-52.9 \\
+327.5\end{array}$ & $\begin{array}{l}-65.3 \text { to }-40.5 \\
208.0 \text { to } 446.0\end{array}$ & $\begin{array}{l}<0.001 \\
<0.001\end{array}$ \\
\hline
\end{tabular}


imperative to also assess for changes in admission rates, diagnoses, and acuity. For example, in one study, although a reduction in overall ED visits was not observed, geographic areas with greater increases in insurance coverage after reform had the largest decrease in ED visits for conditions classified as nonurgent, primary care-treatable, and primary care-preventable, along with an increase in ED visits for nonpreventable emergencies. ${ }^{29}$ These findings suggest that even though ED visits did not decrease in aggregate, the manner in which patients access emergency services may change. In future studies, we plan to focus on such granular detail to allow for a better understanding of the demands for ED and non-ED health care services.

Our findings suggest that expanding insurance coverage to adolescents improved access to health care services and shifted use to non-ED settings. Comparisons with young adults, a group not targeted by national coverage initiatives during this same time period, demonstrated their increasing use of ED services, while visits to outpatient departments remained relatively flat. This comparison underscores the importance of the provision of affordable health insurance in facilitating access to outpatient health care services overall. With regard to the trend of increasing ED use for young adults over time, it is important to consider that this population may have a higher demand for acute medical care compared to adolescents. Other investigators have found that young adults (20 to 29 years of age) were more likely than children ( 0 to 18 years of age) to be seen in the ED for injuries, as well as for noninjury conditions. $^{33}$

\section{LIMITATIONS}

Our analysis uses CHIP as a natural experiment to assess the policy effects of prior national initiatives to expand health insurance on subsequent use of health care services. In such an observational study, we are unable to control for potential confounders such as other secular trends, including the changing influence of health care management organizations or new pediatric guidelines during this time period, which may be associated with health care use patterns. Therefore, in an effort to reveal potential secular trends, we felt it was important to include the young adults as a control.

We considered the young adult age group to be an appropriate control group due to their similarities to adolescents. Persons in the third decade of life are traditionally healthy and therefore not expected to require frequent health care visits for chronic disease management. They are also similar to adolescents because they often interface with health care systems for primarily acute care needs such as injuries. We do, however, recognize that adolescents and young adults may not match as well regarding access to motor vehicles, as well as drugs and alcohol. Increased access to these factors could contribute to greater risk for injury in the young adult population and increased likelihood to seek ED services.

In addition, as an ecologic study using visit-level aggregate data, we are unable to examine individual- level variation. Therefore, we are unable to attribute these trends to individual health care-seeking behaviors. Visit-level data are useful in assessing overall demand for medical services, but do not allow us the ability to determine whether the trends observed are from one person who visited several times or several persons who visited once. Therefore, in an effort to assess the validity of our results, we also performed analyses of utilization trends by payer and sex.

Another important consideration is the limited number of years in the pre-CHIP baseline time period. We sought to capture simultaneous trends in ambulatory care use at the population level; however, the survey years that include both ED and outpatient visits were limited to 1992 onward.

\section{CONCLUSIONS}

Our study highlights the association of the Children's Health Insurance Program with national patterns of ambulatory health care utilization. We found in the Children's Health Insurance Program target population that use of outpatient services increased, while ED volumes did not decrease over time. In this context, the outpatient-to-ED ratio may be an informative measure for gauging the overall effect of future coverage initiatives on both ED and non-ED outpatient use.

Understanding population demand for ambulatory care services and trends related to where patients opt to seek care can inform interventions to improve coordination and use of health care services. It may also highlight persistent disparities or barriers that limit use of primary and preventive care services and contribute to overreliance on ED services. Developing a better understanding of patient decision-making and preferences in changing circumstances of individual coverage may inform development of patient-centered interventions to address the increasing demand for acute care services at the population level with national coverage expansion. Our findings have particular relevance as our country prepares for a large-scale expansion of health care coverage. As the implementation of the Affordable Care Act moves forward, it will be vital to develop a comprehensive understanding of how these policies affect use of health care services in ED and non-ED outpatient settings.

Drs. Haggins and Patrick are grateful for the support of the Robert Wood Johnson Foundation Clinical Scholars Program. The views expressed herein are solely those of the authors and do not necessarily reflect the views of the Robert Wood Johnson Foundation. Dr. Haggins is also thankful to Hwajung Choi, PhD, for her patience and insight in assisting with the data analysis.

\section{References}

1. U.S. House of Representatives. Committee on Ways and Means. Hearing on the President's Fiscal Year 2012 Budget Proposal with U.S. Department of Health and Human Services Secretary Kathleen Sebelius. Available at: http://waysandmeans.house.gov/ News/DocumentSingle.aspx?DocumentID=230472. Accessed Jul 27, 2013. 
2. Li M, Baughman R. Coverage, utilization, and health outcomes of the State Children's Health Insurance Program. Inquiry. 2010; 47:296-314.

3. Urban Institute. Children's Insurance Coverage and Service Use Improve. Available at: http://www.urban. org/publications/310816.html. Accessed Jul 27, 2013.

4. Dubay L, Guyer J, Mann C, Odeh M. Medicaid at the ten-year anniversary of SCHIP: looking back and moving forward. Health Aff (Millwood). 2007; 26:370-81.

5. Hudson JL, Selden TM, Banthin JS. The impact of SCHIP on insurance coverage of children. Inquiry. 2005; 42:232-54.

6. Kenney G, Yee J. SCHIP at a crossroads: experiences to date and challenges ahead. Health Aff (Millwood). 2007; 26:356-69.

7. Quinn A, Rosenbach M. Beyond Coverage: SCHIP Makes Strides Toward Providing a Usual Source of Care to Low-income Children. Mathematica Policy Research, Inc. Available at: http://www.mathematicampr.com/publications/pdfs/schipstrides.pdf. Accessed Jul 27, 2013.

8. Slifkin RT, Freeman VA, Silberman P. Effect of the North Carolina state children's health insurance program on beneficiary access to care. Arch Pediatr Adolesc Med. 2002; 156:1223-9.

9. Kenney G. The impacts of the state children's health insurance program on children who enroll: findings from ten states. Health Serv Res. 2007; 42:1520-43.

10. Szilagyi PG, Dick AW, Klein JD, Shone LP, Zwanziger J, McInerny T. Improved access and quality of care after enrollment in the New York state children's health insurance program (SCHIP). Pediatrics. 2004; 113:e395-404.

11. Duderstadt KG, Hughes DC, Soobader MJ, Newacheck PW. The impact of public insurance expansions on children's access and use of care. Pediatrics. 2006; 118:1676-82.

12. Hoilette LK, Clark SJ, Gebremariam A, Davis MM. Usual source of care and unmet need among vulnerable children: 1998-2006. Pediatrics. 2009; 123:e214-9.

13. Agency for Healthcare Research and Quality. Table 1. Total Utilization and Mean Expenses per Visit by Type of Ambulatory Health Care Service, 2009. Available at: http://meps.ahrq.gov/mepsweb/data_stats/summ_tables/hc/mean_expend/2009/table1.pdf. Accessed Jul 27, 2013.

14. Ginde AA, Lowe RA, Wiler JL. Health insurance status change and emergency department use among US adults. Arch Intern Med. 2012; 172: 642-7.

15. Centers for Disease Control and Prevention. NAMCS/NHAMCS Survey Methodology. Scope and Sample Design. Available at: http://www.cdc.gov/ nchs/ahcd/ahcd_scope.htm\#namcs_scope. Accessed Jul 27, 2013.

16. Centers for Disease Control and Prevention. NAMCS Estimation Procedures. Available at: http://www.cdc.gov/ nchs/ahcd/ahcd_estimation_procedures.htm\#namcs_ procedures. Accessed Jul 27, 2013.

17. Center for Disease Control and Prevention. NHAMCS Estimation Procedures. Available at: http://www.cdc. gov/nchs/ahcd/ahcd_estimation_procedures.htm\#nha mcs_procedures. Accessed Jul 27, 2013.
18. American Medical Association. GAPS Recommendations Monograph. Available at: http://www. ama-assn.org//resources/doc/ad-hlth/gapsmono.pdf. Accessed Jul 27, 2013.

19. Centers for Medicare \& Medicaid Services. Medicaid and CHIP Program Information By Population: Children. Available at: http://www.medicaid.gov/ Medicaid-CHIP-Program-Information/By-Population/ Children/Children.html. Accessed Jul 27, 2013.

20. Newacheck PW, McManus MA, Gephart J. Health insurance coverage of adolescents: a current profile and assessment of trends. Pediatrics. 1992; 90:58996.

21. Newacheck PW, Brindis CD, Cart CU, Marchi K, Irwin CE. Adolescent health insurance coverage: recent changes and access to care. Pediatrics. 1999; 104:195-202.

22. Ziv A, Boulet JR, Slap GB. Utilization of physician offices by adolescents in the United States. Pediatrics. 1999; 104:35-42.

23. Rand CM, Shone LP, Albertin C, Auinger P, Klein JD, Szilagyi PG. National health care visit patterns of adolescents: implications for delivery of new adolescent vaccines. Arch Pediatr Adolesc Med. 2007; 161:252-9.

24. The Henry J. Kaiser Family Foundation. Children's Health Insurance Program Reauthorization Act of 2009 (CHIPRA). Available at: http://www.kff.org/ medicaid/upload/7863.pdf. Accessed July 27, 2013.

25. Wagner AK, Soumerai SB, Zhang F, Ross-Degnan D. Segmented regression analysis of interrupted time series studies in medication use research. J Clin Pharm Ther. 2002; 27:299-309.

26. Newacheck PW, Stoddard JJ, Hughes DC, Pearl M. Health insurance and access to primary care for children. N Engl J Med. 1998; 338:513-9.

27. Lieu TA, Newacheck PW, McManus MA. Race, ethnicity, and access to ambulatory care among US adolescents. Am J Public Health. 1993; 83:9605.

28. Smulowitz PB, Lipton R, Wharam JF, et al. Emergency department utilization after the implementation of Massachusetts health reform. Ann Emerg Med. 2011; 58:225-34.

29. Miller SM. The effect of insurance on outpatient emergency room visits: an analysis of the 2006 Massachusetts health reform. Soc Sci Res Netw. 2012; 96:893-908.

30. Finkelstein A, Taubman S, Wright B, et al. The Oregon health insurance experiment: evidence from the first year. Q J Econ. 2012; 127:1057-106.

31. Baicker K, Finkelstein A. The effects of Medicaid coverage - learning from the Oregon experiment. N Engl J Med. 2011;25;365:683-5.

32. Long SK, Stockley K, Dahlen H. Massachusetts health reforms: uninsurance remains low, selfreported health status improves as state prepares to tackle costs. Health Aff (Millwood). 2012; 31:444 51.

33. Fortuna RJ, Robbins BW, Mani N, Halterman JS. Dependence on emergency care among young adults in the United States. J Gen Intern Med. 2010; 25:663-9. 